\title{
UMA LEITURA FOUCAULTIANA DAS CARTAS DE SÊNECA: CUIDADO DE SI, ESCRITA DE SI, LEITURA DE SI
}

\author{
A FOUCAULTIAN READING OF SENECA'S LETTERS: \\ SELF-CARE, SELF-WRITING, SELF-READING
}

\section{UNA LECTURA FOUCAULTIANA DE LAS CARTAS DE SÉNECA: AUTOCUIDADO, AUTOESCRITURA, AUTOLECTURA}

\author{
David da Silva Pereira ${ }^{1}$ \\ Silvana Dias Cardoso Pereira ${ }^{2}$
}

\begin{abstract}
Resumo: Michel Foucault ensinou no Collège de France entre 02 dez. 1970 e 25 jun. 1984, de sua aula inaugural ao seu desaparecimento. Nesse último ano, profere o Curso "A Coragem da Verdade", por meio do qual, compartilha uma certa forma de interpretação das Cartas de Sêneca no âmbito de uma investigação sobre a aleturgia - processos de produção do dizer verdadeiro. Esta comunicação estende-se ainda um artigo publicado em 1983, em uma série de estudos e conferências sobre as artes de si, para restituir elementos de um conjunto de atos de cuidado, de escrita, de leitura de si, a partir de um trabalho realizado estritamente sobre esses escritos e sobre o que eles deixaram de contribuição para o pensamento no presente. Nessas conferências, meses antes, Foucault já anunciara, de modo específico em sua quarta Conferência, aspectos fundamentais dessas práticas estoicas em um contexto de aprofundamento de uma investigação acerca do cuidado de si e da parresía em seus três últimos Cursos do Collége. Evidenciam-se os efeitos desses exercícios na transformação do sujeito, na autoconstituição do sujeito, na transformação de si por meio da relação com o outro a partir dos elementos oferecidos pela compreensão foucaultiana.
\end{abstract}

Palavras-chave: Cuidado de si; escrita de si; leitura de si.

\begin{abstract}
Michel Foucault taught at the Collège de France between December 2, 1970 and June 25, 1984, from his inaugural class to his disappearance. In this last year, he has given the Course "The Courage of Truth", through which he shares a certain form of interpretation of Seneca's Letters in the context of an investigation on alleturgy - processes of production of true speech. This Communication also extends to an article published in 1983, in a series of studies and conferences on the arts of the self, to restore elements of a set of acts of care, writing, reading of the self, based on a work performed strictly about these writings and what they have left as a contribution to thought in the present. In these conferences, months before, Foucault had already announced, specifically in his fourth Conference, fundamental aspects of theses stoic practices in a context of deepening an investigation about self-care and parresía in his last three Collège Courses. The effects of these exercises are evidenced in the transformation of the subject, in the self-constitution of the subject, in the transformation of oneself through the relationship with the other, based on the elements offered by Foucault's understanding.
\end{abstract}

Keywords: Self care; writing yourself; reading of self.

Resumen: Michel Foucault enseño en el Collège de France entre el 2 de diciembre de 1970 y el 25 de junio de 1984, desde su clase inaugural hasta su desaparición. Em este último año ha impartido el Curso "El Coraje de la Verdad", a través del cual comparte una cierta forma de

\footnotetext{
${ }^{1}$ Universidade Tecnológica Federal do Paraná - Campi Cornélio Procópio.

${ }^{2}$ Doutora em Educação - Unicamp.
} 
interpretación de las Cartas de Séneca em el contexto de una investigación em alleturgia procesos de producción del verdadero dicho. Esta comunicación se extiende también a un artículo publicado em 1983, em una serie de estudios y conferencias sobre las artes del yo, para restaurar elementos de un conjunto de actos de estudios y conferencias sobre las artes del yo, para restaurar elementos de un conjunto de actos de cuidado, escritura, lectura del yo, basados em un trabajo realizado estrictamente sobre estos escritos y lo que han dejado como aporte al pensamiento del presente. Em estas jornadas, meses antes, Foucault ya había anunciado, concretamente em su cuarta Jornada, aspectos fundamentales de estas prácticas estoicas em un contexto de profundización de una investigación sobre autocuidado y parresia en sus últimos tres Cursos del Collège. Los efectos de estos ejercicios se evidencian em la transformación del sujeto, em la autoconstitución del sujeto, em la transformación de un mismo a través de la relación con el otro, a partir de los elementos que ofrece la comprensión de Foucault.

Palabras clave: Autocuidado; autoescritura; autolectura.

\section{Introdução}

As comunicações anuais de Michel Foucault sobre o estágio atual de suas investigações tinham lugar, a cada início de ano (jan.-abr.) em um dos anfiteatros do Collège de France. Desde 1970, momento em que proferiu A Ordem do Discurso ${ }^{3}$, habitou-se a esse contato com um público indefinido e cambiante que crescera durante os anos 1970 a ponto de ser necessário ampliar o espaço de acolhida para mais um anfiteatro.

Em que pese as suas estratégias de alteração do dia da semana e do horário dos encontros, com o propósito de, a cada ano, reduzir esse público, tratava-se de um acontecimento descrito em várias notas de rodapé das transcrições dos Cursos e, também, na apresentação das edições francesas publicadas post mortem.

No último triênio de sua existência, Foucault já conhecia o adoecimento causado pela Síndrome da Imunodeficiência Adquirida (SIDA ${ }^{4}$ ) e escolheu, como final apoteótico, dar um salto no abismo, um mergulho em si, ao modo de uma espécie de prestação de contas consigo, em especial, no último Curso - identificado inicialmente nos escritos do Collège de France como O Governo de Si e dos Outros II (como continuação do Curso de 1983) - mas substituído por A Coragem da Verdade (2011a) na publicação editorial posterior como título principal para ficar como subtítulo.

É interessantíssimo observar esse mergulho sem retorno, essa retomada na Antiguidade do cuidado de si e da parresía para retornar à apropriação mais tarde realizada pelo pastorado de todo um processo de subjetivação que implica no governo do outro. Essa alteração, pouco discutida pelos estudiosos desse autor, desloca o foco do poder para a ética. Desloca a centralidade da governamentalidade para o dizer a verdade a qualquer custo. Para elaborar, a partir de si, um discurso que expõe em absoluto e que leva às últimas consequências uma prática filosófica concebida pelos cínicos como armadura de vida a partir da leitura foucaultiana.

Contudo, antes de chegar aos cínicos, Foucault atualiza em cada contexto e em cada corrente filosófica o significado e o modo de expressão e de prática da parresía. Essa coragem de dizer a verdade, entre orador e plateia, entre mestre e discípulo, entre o conselheiro e o príncipe, que havia sido tomada a partir de Édipo-Rei em 1982 - A Hermenêutica do Sujeito (HS) (FOUCAULT, 2010a), que é retomada com Íon em 1983 - O Governo de Si e dos Outros (GSA) (FOUCAULT, 2010b), agora é repassada como que em um caleidoscópio em 1984 - A Coragem da Verdade (CV).

\footnotetext{
${ }^{3}$ Aula pronunciada em 02 dez. de 1970 e publicada originalmente pela Édittions Gallimard, Paris, em 1971. Há traduções em português pelas editoras Loyola (1996, 3. ed.) e Publifolha (2015).

${ }^{4}$ Sigla em língua portuguesa para a Acquired Immuno Deficiency Syndrome (AIDS).
} 
Dessas práticas de si que tecem a subjetividade, importa muito entre os estoicos, o cuidado de si estabelecido como uma ética de si, como um conjunto de práticas de reelaboração de si contínua, que mobilizam atividades como a reflexão, a escrita e a leitura. Em um evento que tem como centralidade a Leitura, como campo do conhecimento, mas também de práticas, é fundamental retomar essa leitura foucaultiana das Cartas de Sêneca para pensar o papel que essa personagem exercia, como uma espécie de diretor de consciências, mas, também, de administrador de um sofrimento existencial, de uma terapêutica espiritual que dizia respeito à própria prática das concepções estoicas.

Sêneca é central porque pratica um cuidado que supera distâncias, muitas distâncias, para confortar, para curar e para trazer um contraponto importante ao presente à vertigem provocada pelo neoliberalismo global, que faz com que a Economia e as Finanças substituam a centralidade das relações, que individualiza, restringe e faz sofrer.

Dessa forma, retomar Sêneca e suas práticas vinculadas a um cuidado de si que é também um cuidado com o outro, um exercício de maestria do cuidado iniciado em Sócrates, é uma oportunidade de retomar a leitura das conferências e desse último Curso de Michel Foucault no Collège de France. Sem a preocupação de esgotar as citações de Foucault sobre Sêneca em cada um dos Cursos, pretende-se reunir elementos para pensar o cuidado, a escrita e a leitura de si.

\section{Cartas de Sêneca na Hermenêutica do Sujeito (HS)}

Na HS, Foucault menciona Sêneca a propósito da construção de uma cultura de si. No percurso de pensar o cuidado de si desde Sócrates, esse estoico é lembrado em várias passagens.

Mais à frente, o nono parágrafo da primeira hora da primeira aula, de 06. jan. 1982 (FOUCAULT, 2010a), trata do terceiro ponto da noção de epimeléia heautô̂ (cuidado de si) e suas relações com o ghôthi seautón (conhece-te a ti mesmo). Sêneca comparece no processo de constituição de uma cura sui (cuidado de si em latim) como "um princípio fundamental para caracterizar uma atitude filosófica ao longo de toda a cultura grega, helenística e romana" (FOUCAULT, 2010a, p. 10). Cita uma Carta de Sêneca (De beneficiis, livro VII, primeiros parágrafos) para tratar de uma passagem sobre Demétrio, o cínico: “O cínico explica [...] quão inútil é ocupar-se em especular sobre certos fenômenos naturais [...] devendo-se, antes, dirigir o olhar para as coisas imediatas que concernem a nós mesmos e para certas regras pelas quais podemos nos conduzir e controlar o que fazemos (FOUCAULT, 2010a, p. 10, grifos nossos).

Dirigir o olhar para si e para certas práticas de si anunciam o que, para os latinos, significou a ideia de cura sui, de importância capital para os estoicos, segundo Foucault (2010a).

No quinto parágrafo da primeira hora da terceira aula, de 20. jan. 1982, emergem dessa análise do cuidado de si na Antiguidade, alguns significados próprios trabalhados por Sêneca, na primeira Carta destinada a Lucilius:

É preciso 'reivindicar-se a si mesmo' [...] quer dizer, é preciso colocar a reinvindicação jurídica, fazer valer seus direitos, os direitos que se tem sobre si mesmo, sobre o eu que se acha atualmente carregado de dívidas e obrigações das quais deve livrar-se, ou que está escravizado (FOUCAULT, 2010a, p. 10, grifos nossos).

É muito instigante essa indisponibilidade para si indicada por Sêneca, muitíssimo atual na terceira década do século XXI. Mas por que se está indisponível? Porque ocupado por dívidas, obrigações e até mesmo escravizado por uma série de demandas outras, insuportáveis 
e incompatíveis com o cuidado de si, consigo. Como diz Foucault (2010a, p. 79), "há pois que liberar-se, desobrigar-se" para concentrar-se no que importa.

No décimo parágrafo da primeira hora, da primeira parte do terceiro capítulo, Sêneca retorna em um conjunto de exemplos sobre essas práticas de si (FOUCAULT, 2010a), após Serenus o consultar sobre conselhos acerca do seu estado de alma (para curá-lo):

Sêneca no começo do De tranquillitate escreve [...] uma carta a Sêneca que lhe dê conselhos, emita um diagnóstico e faça para com ele, de certa maneira, o papel de um médico da alma. Ora, esse Serenus [...] (era) um homem jovem, da província [...] que chegara a Roma onde começara uma carreira de homem político e até de cortesão (FOUCAULT, 2010a, p. 81, grifos nossos).

Observa-se uma aproximação da prática realizada por Sêneca de uma espécie de cura da alma, de algo que se apresenta como uma prescrição, uma terapêutica apta a restaurar o espírito do interlocutor. Fundamental é considerar que, nesse processo epistolar, articulam-se ações como o pensar sobre si, o escrever sobre si, o ler sobre si e também sobre o outro. É por meio dessa anamnese escrita que é possível a Sêneca administrar a prescrição.

Trata-se de uma prática de atos, fundados no estoicismo, mas que conformam também um certo realinhamento, uma espécie de conversão a si fundada em práticas de cuidado. Nesse esforço de buscar um diagnóstico e uma terapêutica, há, sem dúvida, um processo de concentração da atenção em si, um esforço de descrição do que vai, do que acontece, do que perturba a si para o outro. É o suficiente, no momento, para resgatar o que Foucault pretende a partir de Sêneca acerca do cuidado de si e das práticas de existências que convergem para o si nesse processo hermenêutico do sujeito, de constituição, mas também de restauração de sua subjetividade.

\section{Cartas de Sêneca em O Governo de Si e dos Outros (GSA)}

Em GSA, Foucault ensaia novamente uma espécie de retrospectiva de seus estudos, de suas investigações sobre a cultura greco-latina arcaica.

Apenas em dois momentos.

No primeiro, nos oitavo e nono parágrafos da primeira hora da segunda aula, de 12. jan. 1983, Sêneca aparece nesse penúltimo curso do Collège de France, mas agora vinculado à parresía. Ao listar os filósofos que conformam "a longa duração dessa noção" na Antiguidade (FOUCAULT, 2010b, p. 46).

No segundo, no oitavo parágrafo da primeira hora da última aula, de 9. mar. 1983, a parresía é agora relacionada a um certo êthos, um modo de viver. Dirige-se a uma "certa maneira de se dirigir aos que governam" e que assume, por vezes, "a forma de educação do príncipe" (FOUCAULT, 2010b, p. 312). Tal finalidade é relacionada a Sêneca, sem mais explicações.

É muito interessante que a construção foucaultiana toma Sêneca apenas pontualmente, em vista da centralidade na análise da obra de Eurípedes - Íon - mas, não deixa o filósofo francês de completar: "logo a Filosofia é uma forma de vida, é também uma espécie de ofício, ao mesmo tempo privado e público, de aconselhamento político. Isso me parece ser uma dimensão constante na Filosofia Antiga" (FOUCAULT, 2010b, p. 312, grifos nossos).

Vale a pena lembrar, mais uma vez, que a parresía - essa coragem da verdade - integra, junto com o cuidado de si, uma cultura das artes de si. 


\section{Cartas de Sêneca na Coragem da Verdade (CV)}

Na CV, Foucault menciona Sêneca em sua narrativa acerca de si, de sua obra, de seu percurso filosófico por meio de uma derradeira prestação de contas consigo.

Logo no início, no quinto parágrafo da primeira hora da primeira aula, de $1^{\circ} \mathrm{fev} .1984$, Sêneca comparece nesse processo de rememoração de um conjunto de investigações quando é mencionada a análise histórica das práticas do dizer-a-verdade sobre si mesmo (parresía):

Podemos citar, em apoio e ilustração dessa importância na cultura antiga, práticas tão frequentemente, tão constantemente, tão continuamente recomendadas [como] o exame de consciência prescrito pelos pitagóricos ou pelos estoicos, de que Sêneca deu exemplos tão desenvolvidos e que voltamos a encontrar em Marco Aurélio. Podemos citar também algumas práticas como essas correspondências, essas trocas de cartas morais, espirituais, de que Sêneca, Plínio, o Moço, Frontão e Marco Aurélio dão exemplos (FOUCAULT, 2011a, p. 5, grifos nossos).

Sêneca é o exemplo de práticas de direção de consciências por meio de correspondências, com caráter de exercícios espirituais, de cura, cuidado de si.

A noção de parresía, segundo Foucault, deixou muitos vestígios, também em Sêneca:

Podemos encontrar muitos exemplos notadamente em Sêneca, onde a prática da parresía é bem delineada por uma série de descrições, de caracterizações, praticamente sem que a palavra seja empregada, quando mais não fosse em razão das dificuldades [encontradas pelos] latinos para traduzir a palavra parresía (FOUCAULT, 2011a, p. 8, grifos nossos).

A parresía como prática, ainda que não denominada diretamente, mas integrada à interlocução de Sêneca com o outro, com um trabalho de si sobre si e, também, sobre o outro. Nesse esforço de prestação de contas consigo, conclui: "a articulação entre os modos de veridiç̧ão, as técnicas de governamentalidade e as práticas de si é, no fundo, o que sempre procurei fazer" (FOUCAULT, 2011a, p. 9).

Com Foucault, dá-se um salto até o quarto parágrafo da primeira hora da sexta aula, de 7 mar. 1984, para falar do cínico Demétrio por meio de Sêneca. Diz Foucault:

Sêneca cita-o com frequência, sempre muito elogiosamente, chamando-o de 'nosso Demétrio', e dizendo que ele é sem dúvida uma das figuras mais notáveis da Filosofia de seu tempo, se não da Filosofia de todos os tempos. (...) Sêneca conta, no De beneficiis (livro VII), que recusara nitidamente, violentamente, uma soma considerável que o imperador, no caso Calígula, teria lhe oferecido (FOUCAULT, 2011a, p. 171, grifos nossos).

Observe-se que Foucault, em seu processo de investigação, utiliza-se de comentários de autores clássicos, como Sêneca, sobre outras personagens da trama que tece acerca dos cínicos e de sua Filosofia como armadura da vida.

No vigésimo segundo parágrafo da primeira hora dessa mesma sexta aula, de 7 mar. 1984, é justamente essa condição, do ensino cínico segundo Foucault, que é objeto do livro VII do $D e$ beneficiis, ainda sobre Demétrio quanto a um "ensino de luta": 
'É com razão que Demétrio, o Cínico, grande homem a meu ver, mesmo em comparação com os maiores, costuma dizer que é mais proveitoso conhecer poucos sábios preceitos a nosso alcance e a nosso uso do que aprender muitos que não temos à mão. Do mesmo modo que um lutador hábil não é o que aprendeu a fundo todas as posições e todas as complicações dos movimentos cujo uso é raro no combate, mas aquele que, tendo se exercitado longa e cuidadosamente em uma ou duas delas, espia atentamente a oportunidade de aplicá-las. Porque não the importa saber muito contanto que saiba o bastante para vencer; assim também, nesse estudo, há muitas coisas que agradam, mas bem poucas que garantem a vitória' (SÊNECA apud FOUCAULT, 2011a, p. 182, grifos nossos).

Impressiona, na descrição realizada por Sêneca, a concepção do ensino como enfrentamento. Luta que oferece o necessário para prevalecer no combate, mas, também, retoma a questão do exercício contínuo ao longo da vida a partir de um trabalho de si sobre si que o aproxima do próprio Sêneca.

Novo salto para, agora, o segundo parágrafo da segunda hora da antepenúltima aula de Foucault no Collège de France, de 14 mar. 1984, encontra um Sêneca empregado para tratar de "uma vida não dissimulada", uma "verdadeira vida" (FOUCAULT, 2011a, p. 221).

Para Sêneca, no destaque de Foucault:

A verdadeira vida que a gente deve viver como se estivesse sempre diante do olhar dos outros em geral, mas sobretudo e de preferência diante dos olhos, do controle, do amigo, o amigo que é ao mesmo tempo o guia exigente e a testemunha. Para Sêneca, a própria prática da correspondência, da troca de cartas, tornando presentes um ao outro o autor da missiva e seu destinatário, tinha precisamente esse papel de pôr de certo modo a existência dos dois correspondentes ante o olhar de cada um deles, cada um ante o olhar do outro. De um lado, o autor da carta constitui, para aquele a quem ele endereça seus conselhos e suas opiniões, uma espécie de olho, de princípio de vigilância (FOUCAULT, 2011a, p. 221-2, grifos nossos).

Mais uma vez, uma imagem foucaultiana do espelho, dos olhos, do olhar o outro. Isso significa que, como Sêneca diz a Lucilius, algo sobre controle das ações, mas, também, diante de hesitações, um exercício importante de pôr a sua vida ante o olhar do outro.

Assim, conclui Foucault, "a correspondência é uma prática de verdadeira vida como vida não dissimulada, isto é, como vida diante do olhar ao mesmo tempo real e virtual do outro" (FOUCAULT, 2011a, p. 222).

Assim, observam-se vários sentidos empregados nessa troca de cartas promovidas por Sêneca com seus interlocutores que mereceram registro, por Foucault, em seu último Curso.

\section{Conferências e entrevistas}

Em uma conferência pronuncia originalmente em 1983 (FOUCAULT, 2017), a escrita de si é tematizada em uma ética hupomnêmata, muito centrada no cuidado de si. Foucault (2017, p. 146) salienta que uma "formação de si” é constituída a partir de "efeitos de limitação devidos à junção da escrita com a leitura".

Sêneca é justamente o primeiro autor mencionado nesse contexto, pois: 
Insiste nisto: a prática de si implica a leitura, pois não se poderia extrair tudo do seu próprio âmago nem se prover por si mesmo de princípios racionais indispensáveis para se conduzir [...]. Mas, não é preciso dissociar leitura e escrita; deve-se 'recorrer alternadamente' a essas duas ocupações, e 'moderar uma por intermédio da outra'. Se escrever muito esgota [...], o excesso de leitura dispersa (FOUCAULT, 2017, p. 146, grifos nossos).

Importante é observar a associação realizada em Sêneca entre a leitura e a escrita. Por outro lado, é possível perceber que escrita e leitura são ações não naturais, razão pela qual demandam esforço, dedicação, concentração e conversão a si.

Mais uma vez, a escrita é colocada em destaque na leitura foucaultiana sobre as práticas de Sêneca, agora na Carta V, novamente a Lucilius, parágrafos primeiro e segundo:

A escrita, como maneira de recolher a leitura feita e de se recolher nela, é um exercício racional que se opõe ao grande defeito da stultitia, possivelmente favorecida pela leitura interminável. A stultitia se define pela agitação da mente, pela instabilidade da atenção, pela mudança de opiniões e vontades, e consequentemente pela fragilidade diante de todos os acontecimentos que podem se produzir; caracteriza-se também pelo fato de dirigir a mente para o futuro, tornando-a ávida de novidades e impedindo-a de dar a si mesmo um ponto fixo na posse de uma verdade adquirida (FOUCAULT, 2017, p. 146-147, grifos nossos).

Muitas dessas agitações, instabilidades, mudanças, fragilidades assaltam o presente. Contra isso, Sêneca, destacado por Foucault, orienta dosar leitura e escrita a fim de escapar da estultícia, da oscilação vivenciada por Lucilius.

Contudo, o sentido das Cartas de Sêneca pode ser tomado a partir da página seguinte desse texto (FOUCAULT, 2017, p. 150, grifos nossos):

As Cartas de Sêneca mostram uma atividade de direção exercida por um homem idoso e já aposentado sobre um outro que ainda ocupa importantes funções públicas. Porém, nessas cartas, Sêneca não se limita a se informar sobre Lucilius e seus progressos; não se contenta em dar-lhe conselhos e comentar para ele alguns grandes princípios de conduta. Através dessas lições escritas, Sêneca continua a se exercitar, devido a dois princípios por ele frequentemente invocados: o de que é necessário adestrar-se durante toda a vida, e o de que sempre se precisa da ajuda de outro na elaboração da alma sobre si mesma.

Há muito aí. Em primeiro lugar, Sêneca se informa, aconselha e comenta princípios de conduta. Em segundo, exercita-se como que por meio de um adestramento, de uma repetição incessante de atos de consciência, mas sem perder, e isso é fundamental, a necessidade do outro nessa reelaboração de si. Extraordinário é ver reiterada a necessidade do outro na prática do cuidado de si. Nesse momento, a metáfora do espelho tão bem colocada no início do Curso de 1984 (CV) é fundamental.

Em um esforço de resgate de uma "evolução das técnicas de si" (segundo subtítulo após uma breve introdução do texto de 1988), Foucault inicia uma síntese da cultura de si justamente no início da primeira conferência um dos seminários proferidos na University of Vermont, Estados Unidos, em 1982, sobre as Tecnologias de Si (FOUCAULT, 2014). Sêneca emerge, justamente, na segunda parte do item III, relacionado à ideia de exame de consciência, que varia também conforme o modo e a finalidade no tempo, mas, agora, a partir de o De ira e o De tranquilitate. Ao contrário da função de purificação entre os pitagóricos, no período helenístico e início do Império, tal prática apresentará outro objetivo (FOUCAULT, 2014). A partir do De 
ira, Foucault resgata de Sêneca alguns traços dessa tradição, também presente entre os epicuristas, de um processo mnenômico que busca "o agir de acordo com o bem" aliado ao exame de consciência como modo de manter o contato com os deuses (FOUCAULT, 2014, p. 280). Trata-se de uma forma de inventariar, como "um contador que examina as contas ou quando um inspetor da construção examina a obra" (FOUCAULT, 2014, p. 280). O exame de si é, pois, o modo de estabelecer esse inventário - uma espécie de olhar administrativo dirigido sobre a vida - ao modo de "um administrador permanente de si" para "lembrar a verdade de si à memória", lembrar-lhe as regras de conduta, "rememorar o erro" para, finalmente, "encontrar as regras de conduta na memória" (FOUCULT, 2014, p. 280-281).

Em outro momento, já em uma entrevista (FOUCAULT, 2011b, p. 334), Foucault traz um outro Sêneca, agora por meio de uma prática que busca uma verdade do sujeito, o exame de consciência. Não ao modo de uma submissão, mas de um "exercício mnemotécnico, orientado para os princípios da vida correta. Esse exame de consciência (esclarece Foucault) não explicava a verdade fundamentada no eu" como faria mais tarde o monasticismo.

De volta à conferência de 1983, é importante observar que todo esse esforço de Sêneca, porém, é descrito claramente como um investimento detido na construção de uma relação conforme o segundo parágrafo da Carta 34 a Lucilius, livro VI, segundo Foucault (2017, p. 151, grifos nossos): “"Eu te reivindico; tu és minha obra'; 'eu te exortei, incitei e, impaciente com qualquer demora, eu te empurrei sem descanso. Fui fiel ao método, mas hoje exorto alguém que prontamente já partiu e que por sua vez me exorta"”.

Assim, na Carta 35, evoca a retribuição: "evoca a recompensa da perfeita amizade, em que cada um dos dois será para o outro o permanente socorro, a inesgotável ajuda [...]" (FOUCAULT, 2017, p. 151).

Contudo, Foucault destaca que a correspondência vai além da prática hupomnêmata, mais do que um adestramento de si, mas: "constitui também uma certa maneira de se manifestar para si mesmo e para os outros" (FOUCAULT, 2017, p. 152). Isso porque torna o escritor presente para o destinatário:

'Tu me escreves com frequência e te sou grato, pois assim te mostras mais a mim pelo único meio de que dispões. Cada vez que me chega tua carta, eis-nos imediatamente juntos. Se ficamos contentes por termos os retratos de nossos amigos ausentes [...] como uma carta nos regozija muito mais, uma vez que traz os sinais vivos do ausente, a marca autêntica de sua pessoa. O traço de uma mão amiga, impresso sobre as páginas, assegura o que há de mais doce na presença: reencontrar' (SÊNECA apud FOUCAULT, 2017, p. 152, grifos nossos).

Conclui Foucault: “escrever é se mostrar, se expor, fazer aparecer seu próprio rosto perto do outro. E isso significa que a carta é, ao mesmo tempo, um olhar que se lança sobre o destinatário e uma maneira de se oferecer ao seu olhar através do que lhe é dito sobre si mesmo" (FOUCAULT, 2017, p. 152). Trata-se de um trabalho fundamental de si, sobre si, por meio da relação com o outro.

\section{Considerações finais}

Com Foucault, resgata-se das Cartas de Sêneca um papel de doutrinador, uma espécie de irradiador das práticas estoicas. Chama-lhe a atenção que, nessa espécie de irradiação de princípios destinada a um apenas, a um destinatário certo e preciso com determinadas necessidades que ele recebe à luz também dessas concepções do mundo estoico, ele realiza uma interlocução epistolar que funciona como uma anamnese seguida de um receituário processual: 
diagnóstico, prescrição, orientação sobre o como administrar os exercícios espirituais que objetivam uma cura, que possui significados outros, para além do físico.

É esse o Sêneca tomado por Foucault nesse retorno à Cultura Clássica, à cultura grecoromana, percorrendo as mutações de sentido do cuidado de si e de um dizer verdadeiro que conformam uma verdadeira cultura de si. Não é à toa que o próprio Foucault chamará o Estoicismo de idade de ouro desse trabalho de si sobre si.

O Cuidado de si (souci de soi) congrega, portanto, uma série de ações do sujeito sobre si mesmo, mas, que no caso de Sêneca, tem, no outro, um papel fundamental. É o outro da correspondência, é o outro amigo, é o outro com quem se pode apresentar como se é, como se está. A escrita e a leitura jogam assim um papel fundamental nesse conjunto de práticas de si, de artes de si a partir de Sêneca segundo o resgate foucaultiano.

Trata-se de um tratamento do espírito, uma preocupação com a alma que diz respeito a uma espécie de formação ou de preparação para o envelhecimento. Porque é velho, Sêneca pode partilhar com outros determinados sentidos que colhe de sua existência quanto à finitude da vida, quanto ao enfraquecimento das potências físicas, quanto a uma preparação para viver cada dia como se fosse o último.

\section{Referências}

FOUCAULT, M. A hermenêutica do sujeito: curso do Collège de France (1981-1982). Trad. M. A. Fonseca e S. T. Muchail. 3. ed. 3. tir. São Paulo: WMF Martins Fontes, 2010a.

FOUCAULT, M. O governo de si e dos outros: curso do Collège de France (1982-1983). Trad. E. Brandão, 4. tir. São Paulo: WMF Martins Fontes, 2010 b.

FOUCAULT, M. A coragem da verdade: o governo de si e dos outros II. curso do Collège de France (1983-1984). Trad. E. Brandão. São Paulo: WMF Martins Fontes, 2011 a.

FOUCAULT, M. Entrevista com Michel Foucault. In: MOTTA, M. B. (Org.). Ditos e Escritos, vol. I: problematização do sujeito, psicologia, psiquiatria e psicanálise. 3. ed. 2. tir. Trad. V. L. A. Ribeiro. Rio de Janeiro: Forense Universitária, 2011b. p. 331-344.

FOUCAULT, M. As técnicas de si. In: MOTTA, M. B. (Org.). Ditos e escritos, vol. IX: genealogia da ética, subjetividade e sexualidade. Trad. E. Monteiro e I. A. D. Barbosa. Rio de Janeiro: Forense Universitária, 2014. p. 264-295.

FOUCAULT, M. A escrita de si. In: MOTTA, M. B. (Org.). Ditos e escritos, vol. V: ética, sexualidade, política. Trad. E. Monteiro e I. A. D. Barbosa. 3. ed. 3. tir. Rio de Janeiro: Forense Universitária, 2017. p. 141-157.

\section{Sobre os autores}

David da Silva Pereira. Professor do Magistério Superior Federal da Licenciatura em Matemática da Universidade Tecnológica Federal do Paraná - Campi Cornélio Procópio e do Programa de Mestrado Profissional em Ensino (PPGEN) Multicamp Cornélio Procópio e Londrina - Grupo de Pesquisa Observatório de Políticas Públicas (GPOPP). Bacharel em Geografia, Ciências Sociais e Direito; Licenciado em Geografia, Ciências Sociais, Pedagogia e 
Filosofia. Mestre em Geografia Humana e Educação; Doutor em Ciência Política, Pós-Doutor em Filosofia e História da Educação. Multicampi. Líder do Grupo de Pesquisa OPP.

E-mail: davidpereira@utfpr.edu.br.

Silvana Dias Cardoso Pereira. Bacharel em Letras (Por./Ale) - IFCH/USP (1997); Licenciada em Língua Portuguesa - FE/USP (1997); Especialista em Educomunicação ECA/USP (2004); Bacharel em Direito - PUC-Camp (2008); Mestre em Educação - FEUnicamp (2007); Doutora em Educação - FE-Unicamp (2021). Mestrado e Doutorado realizados no âmbito dos trabalhos do Grupo de Pesquisa ALLE-AULA FE-Unicamp. Membro do ALLE-AULA FE-Unicamp; Membro do GPOPP-UTFPR-CP (Vice-líder). E-mail: pereirasilvana319@yahoo.com.br. 